\title{
User preference for a portable syringe pump for iloprost infusion
}

\author{
This article was published in the following Dove Press journal: \\ Patient Related Outcome Measures \\ 19 May 2015 \\ Number of times this article has been viewed
}

\author{
Antonella Laria' \\ Alfredo Maria Lurati' \\ Katia Angela Re \\ Maria Grazia Marrazza' \\ Daniela Mazzocchi' \\ Alberto Farina ${ }^{2}$ \\ Magda Scarpellini' \\ 'Department of Rheumatology, \\ Fornaroli Hospital, Magenta, Milan, \\ Italy; ${ }^{2}$ Medical Affairs Department, \\ Italfarmaco S.p.A., Cinisello Balsamo, \\ Milan, Italy
}

Purpose: Administration of intravenous iloprost - a first-line European League Against Rheumatism (EULAR)-recommended choice for the treatment of scleroderma (SSc)-related digital vasculopathy - requires repeated treatment cycles of 6 hours per day in a hospital setting. During the infusion, patient mobility is considerably restricted due to the size and fixity of traditional syringe pumps. The aim of this study was to evaluate the satisfaction level of patients and nurses, after the introduction of a new portable syringe pump (Infonde ${ }^{\circledR}$, Italfarmaco S.p.A., Milan, Italy) at the Department of Rheumatology, Magenta Hospital, Milan, Italy.

Patients and methods: Thirty-four consecutive SSc patients receiving stable therapy with iloprost, previously administered with a fixed pump, were treated using the portable Infonde ${ }^{\circledR}$ pump. Patients $(n=34)$ and nurses $(n=4)$ were asked to answer a nine- and six-item questionnaire, respectively, to assess the satisfaction of the administration comparing the new device versus the previous one. The health care staff of the ward developed the questionnaire, and the response scores ranged from 0 (fixed device better) to 10 (portable device better); thus a score $>5$ indicates a preference for Infonde ${ }^{\circledR}$.

Results: Patients' answers indicated a preference towards the new portable syringe pump, versus the previous fixed pump. Questionnaires administered to patients generated a total of 306 responses, with over $95 \%$ of the responses in the range $8-10$, of which $89 \%$ had a score equal to 10 . The responses of nurses showed a score equal to 10 in $100 \%$ cases. No significant adverse events were recorded, indicating no change in the tolerability profile of the drug.

Conclusion: Iloprost administration with Infonde ${ }^{\circledR}$ pump was preferred by both patients and health care professionals, and was well tolerated. The possibility to perform daily activities and the freedom of movement suggest a positive impact of Infonde ${ }^{\circledR}$ on the treatment, with a potential favorable effect on the quality of life of patients during the many hours spent receiving the infusion.

Keywords: scleroderma, quality of life, Raynaud's phenomenon, delivery device

\section{Introduction}

Scleroderma (systemic sclerosis or SSc) is a severe, chronic disease whose pathogenesis is characterized by small vessel vasculopathy, production of autoantibodies, and fibroblast dysfunction leading to increased deposition of extracellular matrix. ${ }^{1}$

Severe Raynaud's phenomenon (RP) is the early onset symptom in most SSc patients. RP is defined as episodic, reversible, peripheral ischemia provoked by exposure to a cold environment or emotionally stressful conditions. Classically, constriction of the digital vessels leads to pallor of the fingers, followed by cyanosis secondary to deoxygenation of static venous blood. The recovery phase features reactive hyperemia with resulting erythema. Unpleasant symptoms associated with RP include numbness,
Correspondence: Alfredo Maria Lurati Department of Rheumatology, Fornaroli Hospital, Via Al Donatore di Sangue, 50 - 200I3, Magenta, Milan, Italy Email alfredomaria.lurati@ao-legnano.it 
coldness, and pain; in the most severe cases, these may result in digital ulceration, gangrene, and loss of fingers. ${ }^{2-4}$

Current guidelines of the European League Against Rheumatism (EULAR) for the treatment of SSc recommend intravenous iloprost as first-line drug for the treatment of SSc-related digital vasculopathy to reduce the frequency and severity of SSc-RP attacks and to heal active digital ulcers in patients with SSc. ${ }^{5}$ Iloprost is a stable prostacyclin analogue presenting vasodilating, anti-platelet, cytoprotective, and immunomodulating properties, with long-lasting effects at the level of cutaneous microcirculation. ${ }^{6-8}$ Clinical data show an improvement in the frequency, duration, and intensity of ischemic episodes for up to at least 6 weeks after a short (3- to 6-day) course of intravenous iloprost. Improved healing of active digital ulcers was also reported..$^{9,10}$ Recent studies by Caramaschi et al propose iloprost as a disease-modifying agent for SSc, as a low incidence of the most severe vascular complications, such as pulmonary arterial hypertension, scleroderma renal crisis, and digital necrosis requiring amputation, was observed, ${ }^{11}$ and a delay in beginning iloprost therapy $>18$ months was significantly associated with an increased occurrence of digital ulcers. ${ }^{12}$

Generally, iloprost is infused with cycles of 6 hours/ day for $2-5$ days/month. According to the manufacturer's recommendations, iloprost infusion should be performed under medical supervision in a hospital setting. ${ }^{13}$ Medical supervision allows determining the maximum tolerated dose at the beginning of the treatment and managing the potential occurrence of the most common side effects (eg, headache, nausea, changes in blood pressure) through symptomatic therapy or modification of the infusion rate. ${ }^{13}$ Medical supervision was provided during the clinical development program for the registration of the drug, during which, a specific portable infusion pump was not yet available, preventing the patient from leaving the hospital. Currently, the only approved devices for the administration of iloprost are infusion and syringe pumps. ${ }^{13}$ These standard pumps significantly limit the mobility of patients, which formerly exhibit a reduced quality of life because of the disease,${ }^{14}$ due to the pumps' immobility and considerable size.

Recently, a new portable syringe pump for iloprost infusion (Infonde ${ }^{\circledR}$, Italfarmaco S.p.A., Milan, Italy) was placed on the market, and a study comparing Infonde ${ }^{\circledR}$ versus flow regulator indicated greater satisfaction in favor of the new device by SSc patients and nurses, with a reduction of adverse events related to fluctuations in pressure. ${ }^{15}$

Thus, the aim of our study was to evaluate the satisfaction of patients and nurses, after the introduction of the new device, comparing it with a fixed infusion pump (Alaris ${ }^{\circledR}$ injection pump, Cardinal Health S.p.A, Milan, Italy), at the Department of Rheumatology, Magenta Hospital, Milan, Italy.

\section{Materials and methods}

From July to November 2013, 34 consecutive SSc patients admitted to the Day Hospital of the Department of Rheumatology of Magenta Hospital were treated with iloprost at a dose of $0.5-2 \mathrm{ng} / \mathrm{kg} / \mathrm{min}$ for 6 hours per day, for 1-3 days per month, for the treatment of secondary RP. Patients did not receive the infusion of any other drug. The enrollment period corresponded to the phase of introduction of a new portable syringe pump (Infonde ${ }^{\circledR}$ ) in the ward, which has gradually replaced the previous fixed syringe pump (Alaris) for iloprost administration. Thus a single arm of SSc patients was included in the study, and evaluations were performed after the first administration of a complete treatment cycle with the new portable device for each patient, in a cross-sectional way.

Therefore, SSc patients on stable therapy with iloprost infused by a fixed infusion pump and who underwent the transition to Infonde ${ }^{\circledR}$ during the enrollment period were included in the study, and those who had already received the drug via a portable device were excluded. For all patients, the previous therapeutic scheme was maintained: this precaution allowed attributing any change in tolerance or acceptance of therapy to the device and not to variations in the dose of the drug.

The sample size of 34 patients was selected according to the number of patients treated in our department, so without performing a formal calculation. Since the evaluation of the efficacy of the drug was not the goal of the study, the seasonality of symptoms was not taken into account, and the observation period was limited from July to November 2013, in order to allow all the patients to receive at least one cycle of therapy with the new device. The study was conducted in accordance with the Declaration of Helsinki, and all patients gave their consent to participate in the study.

Patients were asked to answer a questionnaire composed of nine items (Table 1) to assess the satisfaction of the administration with the new device, after at least one administration, in comparison with the standard one. Questionnaires were anonymous and self-completed by patients, in this way, the expectations of the investigators affected the responses of patients as little as possible.

The response scores ranged from 0 (fixed device better) to 10 (portable device better): a score $<5$ points was in favor of the previous device, and a score $>5$ was in favor of Infonde ${ }^{\circledR}$; so a single question compared the satisfaction associated with the two methods of infusion. 
Table I Questionnaire administered to patients

\begin{tabular}{|c|c|c|c|c|c|c|c|}
\hline \multirow[t]{2}{*}{ Item } & \multirow{2}{*}{$\begin{array}{l}\text { Mean } \\
\text { score }\end{array}$} & \multicolumn{6}{|c|}{ Frequency (\%) } \\
\hline & & 10 & 9 & 8 & 7 & 5 & NA \\
\hline I. How would you rate your overall experience with the new device? & $9.9 \pm 0.4$ & 94.1 & 2.9 & 2.9 & 0 & 0 & 0 \\
\hline 2. Do you think that the administration with the new device is safe? & $9.6 \pm 1.8$ & 91.2 & 0 & 5.9 & 0 & 0 & 2.9 \\
\hline $\begin{array}{l}\text { 3. How do you judge the tolerability of the drug administered with } \\
\text { the new device? }\end{array}$ & $9.0 \pm 2.4$ & 70.6 & 8.8 & 8.8 & 5.9 & 0 & 5.9 \\
\hline 4. How would you rate the ease of use of the new device? & $9.9 \pm 0.2$ & 97.0 & 2.9 & 0 & 0 & 0 & 0 \\
\hline 5. How do you perceive your state of health with the new device? & $8.5 \pm 2.9$ & 64.7 & 2.9 & 20.6 & 0 & 2.9 & 8.8 \\
\hline $\begin{array}{l}\text { 6. How would you rate the new device in comparison with the } \\
\text { previous one? }\end{array}$ & $9.9 \pm 0.2$ & 97.0 & 2.9 & 0 & 0 & 0 & 0 \\
\hline $\begin{array}{l}\text { 7. Do you think that the freedom of movement allowed by the new } \\
\text { device is important? }\end{array}$ & $9.7 \pm 1.7$ & 97.0 & 0 & 0 & 0 & 0 & 2.9 \\
\hline $\begin{array}{l}\text { 8. How would you rate the performance of daily activities (eg, eating, } \\
\text { using the toilet, etc) with the new device? }\end{array}$ & $9.7 \pm 1.7$ & 97.0 & 0 & 0 & 0 & 0 & 2.9 \\
\hline 9. In future, if you had the chance, would you choose the new device? & $9.4 \pm 2.4$ & 94.1 & 0 & 0 & 0 & 0 & 5.9 \\
\hline
\end{tabular}

Notes: For each item, the average score \pm standard deviation and frequency of each score that received at least one answer are reported. Scores equal to $0,1,2,3,4$, and 6 were not registered in any case, therefore, the respective frequencies were not reported in the table. NA indicates the case of nonavailable response, which was considered equal to 0 for the calculation of the mean score.

The mean score for each item and the overall mean score were calculated by taking into account the scores of every single response (nine per patient). The results are reported as a value \pm standard deviation; in case of nonavailable response, the score was considered equal to 0 .

The questionnaire - not previously validated for the assessment patient satisfaction or quality of life - was developed from one administered in a previous study ${ }^{15}$ including the most relevant items related to the infusion, according to the opinion of the medical and nursing staff of the ward. In particular, we considered two main domains that related, on one hand, to the safety/tolerability profile of the drug and the perception of health status, as, if negative, they can lead to refusal of treatment; and, on the other hand, the acceptability of the new device and the freedom of movement, as the traditional fixed syringe pumps force the patient to remain in bed for several hours during the infusion, for many days per month.

A similar questionnaire was also administered to the nursing staff $(n=4)$. The questions included the following:

1. How would you rate your overall experience with the new device?

2. How would you rate the patient's approach to the new device (eg, if the patient is willing to use the new device)?

3. How would you rate the method of preparation of the infusion with the new device?

4. How would you rate the programming mode of the new device (initial preparation and programming during the infusion)?

5. How would you rate the safety of the new device?
6. How would you rate the management of the patient with the new device compared to the old one?

At the end of the collection of all responses, a descriptive statistical analysis was performed.

During the observation period, the onset of any clinical or laboratory adverse event possibly related to the drug, reported spontaneously by patients or detected by physicians or nurses, was monitored.

Infonde ${ }^{\circledR}$ is a portable syringe pump with reduced dimensions $(84.9 \times 49.3 \times 32.1 \mathrm{~mm})$ and a weight of $118 \mathrm{~g}$ (Figure 1). It is specifically designed for the controlled administration of intravenous iloprost, and uses dedicated syringes of $25.5 \mathrm{~mL}$. The pump administers doses of $7.44 \mu \mathrm{L}$ at intervals that depend on the flow set. The programming software is designed specifically for the administration of iloprost and for the setup of the infusion; only patient weight and flow velocity need to be entered. The infusion duration may vary from 1 hour to 24 hours.

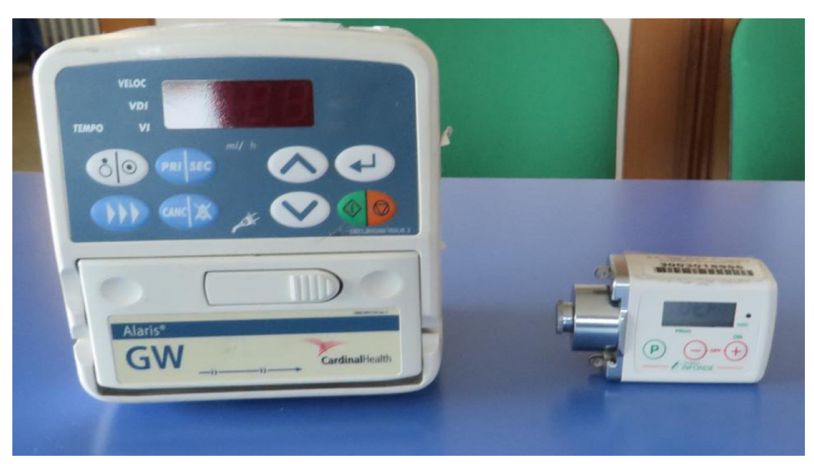

Figure I Alaris ${ }^{\circledR}$ injection pump (left) and Infonde ${ }^{\circledR}$ pump (right). 


\section{Results}

Thirty-four SSc patients were included in the study. Baseline characteristics of the study population are reported in Table 2.

The nine-item questionnaire administered to each patient generated a total of 306 responses. The results indicate a favorable judgment for the new method versus the previous one, as the calculated overall mean score was equal to 9.5 \pm 1.8 . A total of $89 \%(\mathrm{~N}=273)$ had the maximum score of 10 , and over $95 \%(\mathrm{~N}=293)$ were included in the range of $8-10$. However, even the remaining $5 \%$ indicated a favorable score, with the lowest score registered equal to 5 , in a single case, in response to the question: "How do you perceive your state of health with the new device?" (Table 1).

The responses of the four nurses of the ward were equal to 10 in $100 \%$ of cases.

During the observation period, no significant adverse events were recorded.

Table 2 Baseline characteristics of the study population $(\mathrm{N}=34)$ Diagnosis

SSc alone in 19 pts (56\%) SSc overlap with UCTD in 9 pts $(26.50 \%)$

SSc overlap with MCTD in I pt $(2.90 \%)$

SSc overlap with Sjögren's in 2 pts $(5.90 \%)$

SSc overlap with APS in I pt (2.90\%)

SSc overlap with Buerger's in I pt (2.90\%)

SSc overlap with SLE in I pt (2.90\%)

Mean age (years) $\pm S D$

$55.79 \pm 12.72$

Sex (male/female [\%])

$7 / 27(20.5 / 79.5)$

Ethnicity

Mean disease duration (years) \pm SD

Caucasian 100\%

Mean iloprost therapy duration (years)

\pm SD

No of patients with history or presence

of digital ulcers (\%)

No of patients receiving bosentan (\%)

No of patients in current or

$9.29 \pm 4.65$

$5.90 \pm 2.98$

$7(20.5)$

$3(8.8)$

$27(79.4)$

previous DMARD therapy (steroids,

MTX, CYC, CsA, AZA, colchicine,

Hydroxychloroquine) for SSc (\%)

No of patients in emoreologic or

antiplatelet or peripheral vasodilatator

therapy (aspirin and pentoxifylline,

calcium-antagonist) (\%)

Abbreviations: APS, antiphospholipid antibody syndrome; AZA, azathioprine; Buerger's, Buerger's disease; CsA, cyclosporine; CYC, cyclophosphamide; DMARD, disease-modifying anti-rheumatic drug; MCTD, mixed connective tissue disease; MTX, methotrexate; pts, patients; SD, standard deviation; Sjögren's, Sjögren's syndrome; SLE, systemic lupus erythematosus; SSc, scleroderma; UCTD, undifferentiated connective tissue disease.

\section{Discussion}

Our results indicate a remarkable satisfaction with the use of the Infonde ${ }^{\circledR}$ pump, by both patients and nurses.

Throughout the observation period, no adverse events during the administration of iloprost with the new device were recorded, indicating a satisfactory safety profile of the drug, which is dependent on the drug itself rather than by the method of administration. Our observations indicate that the transition to Infonde ${ }^{\circledR}$ pump does not lead to any changes in drug tolerability, and certainly no increase in adverse events. It is interesting to note that these findings are confirmed by the opinions of patients. In fact, the answers to the questions "Do you think that the administration with the new device is safe?" and "How do you judge the tolerability of the drug administered with the new device?" reported a favorable judgment (score between 8 and 10) in 97.1\% and $88.2 \%$ of cases, respectively. Above all, in no case a negative judgment was reported.

The ease of use, the freedom in movement, and the ability to perform common activities of daily living were the most appreciated items by patients; in fact, the previous bulky infusion devices significantly reduced the mobility of individuals, possibly contributing to making them feel even "sicker". This was confirmed by the answers to questions 5-8. Probably, the small size, portability, and reduced visibility of the Infonde ${ }^{\circledR}$ pump played an important role on patient's psychology, making them perceive greater privacy during treatment.

Though evidence-based medicine teaches us that scleroderma is caused by specific organic causes - although still not fully understood - and that the efficacy of iloprost is demonstrated by randomized clinical trials and explained by its mechanism of action, it is interesting to note that the simple use of a modern and portable device was able to improve patients' perception of their own state of health (question 5). In our opinion, the introduction of a new, smaller device can make the therapy more acceptable for the patient, with potential psychological benefits.

The overall positive judgment of patients is confirmed by the responses to question 9: "In future, if you had the chance, would you choose the new device?", since the answers were equal to 10 in $94 \%$ of cases. This is in agreement with our daily clinical practice, as most patients spontaneously ask to be treated with the new device instead of the bulkier and nonmobile ones.

The results obtained by nurses indicate a remarkable favorable judgment of the Infonde ${ }^{\circledR}$ pump. Surprisingly, also for the items related to learning and the use of the new device, 
the maximum score was recorded (questions 3 and 4). This is a relevant issue since new technologies often meet resistance because of the learning process of the functioning of the new devices and the habit of using the old ones. Furthermore, this is significant for iloprost infusions since they should be prepared and administered in hospital settings, under the supervision of health care professionals.

The point of view on the safety profile of the nurses confirms the results obtained from patients; in fact, for the question: "How would you rate the safety of the new device?", a $100 \%$ positive opinion was indicated by health care professionals. Also, the general approach of the patient was confirmed with the answer to question 2: patients were willing to try the new device, without showing resistance to change.

During our experience with the use of the Infonde ${ }^{\circledR}$ pump, we have perceived a reduction - though it was not the predetermined purpose and not investigated through specific quantitative measurements - in the need for continuous monitoring of the patient with a potential improvement in the organization of staff activities in the ward; that was consistent with the positive answer to question 6: "How would you rate the management of the patient with the new device compared to the old one?". This aspect may be relevant, because nurses can carry out other activities, or, on the other hand, a smaller number of nurses can monitor the treatment of scleroderma patients. However, these remarks need to be studied in specific future trials.

Our results are in agreement with those obtained from a previous study comparing Infonde ${ }^{\circledR}$ versus a fixed flow regulator, an effective but unapproved method for iloprost infusion, ${ }^{13,16}$ indicating greater satisfaction in favor of the new device by patients and nurses. ${ }^{15}$ Thus, the results of our study, in which Infonde ${ }^{\circledR}$ was compared with an approved, fixed syringe pump, suggest that the portability and the small size of the pump are important for user satisfaction.

The present study has some limitations. The questionnaire - although developed from a previous study - was not validated for the assessment of patient satisfaction or quality of life. Since the questionnaire was developed by the health care staff of the ward, in order to improve the quality of the evaluation, in future it might be useful to include patients in the development of questions, to avoid the potential omission of any important issue. Furthermore, a single questionnaire compared two devices; in future it may be interesting to use separate questionnaires for each device, and then compare the results. The study design is observational, thus the results need to be confirmed in multicenter randomized trials.
The number of patients included was relatively low, but thanks to the wide satisfaction associated with the new device, it was possible to obtain unequivocal results.

\section{Conclusion}

In conclusion, the administration of iloprost with the new device Infonde ${ }^{\circledR}$ was more appreciated than nonmobile syringe pumps by both patients and health care professionals.

Among the items evaluated, the improvement in the perception of the state of health, the possibility to perform daily activities, and the freedom of movement suggest a generally positive impact of Infonde ${ }^{\circledR}$ on the treatment, possibly with a favorable effect on the quality of life of the patient during the many hours spent receiving the infusion. These factors may have favorable implications in the management of a chronic and severe disease such as scleroderma.

Due to the limitations of the study design, our results need to be further investigated in larger clinical trials, possibly using validated questionnaires for the assessment of quality of life and the evaluation of time savings in patient management.

\section{Disclosure}

Alberto Farina is an employee of Italfarmaco S.p.A. The other authors report no conflicts of interest in this work.

\section{References}

1. Gabrielli A, Avvedimento EV, Krieg T. Scleroderma. $N$ Engl J Med. 2009;360:1989-2003.

2. Galluccio F, Matucci-Cerinic M. Two faces of the same coin: Raynaud phenomenon and digital ulcers in systemic sclerosis. Autoimmun Rev. 2011;10:241-243.

3. LeRoy EC, Medsger TA. Raynaud's phenomenon: a proposal for classification. Clin Exp Rheumatol. 1992;10:485-488.

4. Herrick AL. Pathogenesis of Raynaud's phenomenon. Rheumatology. 2005;44:587-596.

5. Kowal-Bielecka O, Landewé R, Avouac J, et al; EUSTAR Co-Authors EULAR recommendations for the treatment of systemic sclerosis: a report from the EULAR Scleroderma Trials and Research group (EUSTAR). Ann Rheum Dis. 2009;68:620-628.

6. Della Bella S, Molteni M, Compasso S, Zulian C, Vanoli M, Scorza R. Differential effects of cyclo-oxygenase pathway metabolites on cytokine production by T lymphocytes. Prostaglandins Leukot Essent Fatty Acids. 1997;56:177-184.

7. Scorza R, Caronni M, Mascagni B, et al. Effects of long-term cyclic iloprost therapy in systemic sclerosis with Raynaud's phenomenon. A randomized, controlled study. Clin Exp Rheumatol. 2001;19: 503-508.

8. Grant SM, Goa KL. Iloprost. A review of its pharmacodynamic and pharmacokinetic properties, and therapeutic potential in peripheral vascular disease, myocardial ischaemia and extracorporeal circulation procedures. Drugs. 1992;43:889-924.

9. Wigley FM, Seibold JR, Wise RA, McCloskey DA, Dole WP. Intravenous iloprost treatment of Raynaud's phenomenon and ischemic ulcers secondary to systemic sclerosis. J Rheumatol. 1992;19: $1407-1414$ 
10. Wigley FM, Wise RA, Seibold JR, et al. Intravenous iloprost infusion in patients with Raynaud phenomenon secondary to systemic sclerosis. A multicenter, placebo-controlled, double-blind study. Ann Intern Med. 1994;120:199-206.

11. Caramaschi P, Dalla Gassa A, Prati D, et al. Severe vascular complications in patients affected by systemic sclerosis cyclically treated with iloprost. Rheumatol Int. 2012;32:1933-1938.

12. Caramaschi P, Martinelli N, Volpe A, et al. A score of risk factors associated with ischemic digital ulcers in patients affected by systemic sclerosis treated with iloprost. Clin Rheumatol. 2009;28:807-813.

13. Italfarmaco S.p.A. Endoprost (Iloprost Trometamol Solution for Infusion) [Package Insert]. Milano IT: Italfarmaco S.p.A; 2013.
14. Hudson M, Thombs BD, Steele R, et al; Canadian Scleroderma Research Group. Quality of life in patients with systemic sclerosis compared to the general population and patients with other chronic conditions. J Rheumatol. 2009;36:768-772.

15. Faggioli P, Sciascera A, Giani L, Mazzone A. Un nuovo device per la somministrazione di iloprost mediante pompa a siringa portatile: sicurezza, tollerabilità e gradimento [Iloprost infusion by a new device as a portable syringe pump: safety, tolerability and agreement]. It J Med. 2012;6:311-314. Italian.

16. Mazzone A, Vezzoli M, Ottini E, Montagna M, Mazzucchelli I, Dal Canton A. A new method of iloprost administration without a peristaltic pump. Curr Ther Res. 2000;61:452-459.

\section{Publish your work in this journal}

Patient Related Outcome Measures is an international, peer-reviewed, open access journal focusing on treatment outcomes specifically relevant to patients. All aspects of patient care are addressed within the journal and practitioners from all disciplines are invited to submit their work as well as healthcare researchers and patient support groups.
The manuscript management system is completely online and includes a very quick and fair peer-review system. Visit http://www.dovepress. com/testimonials.php to read real quotes from published authors.

Submit your manuscript here: http://www.dovepress.com/patient-related-outcome-measures-journal 